\title{
The Low Salinity Effect at High Temperatures
}

\author{
Quan Xie ${ }^{\mathrm{a}, \mathrm{b}, *}$, Patrick V. Brady ${ }^{\mathrm{c}}$, Ehsan Pooryousefy ${ }^{\mathrm{a}}$, Daiyu Zhou ${ }^{\mathrm{d}}$, Yongbing Liu ${ }^{\mathrm{b}}$, Ali Saeedi ${ }^{\mathrm{a}}$ \\ aDepartment of Petroleum Engineering, Curtin University, 26 Dick Perry Avenue, 6151 Kensington, \\ Western Australia, Australia \\ ${ }^{b}$ State Key Laboratory of Oil and Gas Reservoir Geology and Exploitation, Southwest Petroleum \\ University, Chengdu, Sichuan 610500, China \\ 'Sandia National Laboratories, Albuquerque, New Mexico 87185-0754, United States \\ ${ }^{\mathrm{d} P e t r o C h i n a ~ T a r i m ~ O i l f i e l d ~ C o m p a n y ~}$
}

\begin{abstract}
Low salinity water flooding (LSWF) is increasingly seen as a cost-effective and environmentalfriendly way to enhance oil recovery from sandstone reservoirs. The controlling mechanism for LSWF appears to be wettability alteration through oil and mineral surface interactions, but the specifics of the process, and the effects of temperature and pressure remain unclear. Weshow that water chemistryhas a much larger impact onLSWF than reservoir temperature and pressure, and that low salinity water flooding can be applied to high temperature and high pressure reservoirs.
\end{abstract}

Contact angles were measured betweena sandstone andan oil ( $\mathrm{AN}=3.98 \mathrm{mg} \mathrm{KOH} / \mathrm{g}, \mathrm{BN}=1.3 \mathrm{mg}$ $\mathrm{KOH} / \mathrm{g}$ ) from a reservoir in the Tarim Field in western China in the presence of various water chemistries. Salinity (formation brine, 100X diluted formation brine, and softened water), temperature $\left(60,100\right.$ and $\left.140^{\circ} \mathrm{C}\right)$ and pressure $(20,30,40$, and $50 \mathrm{MPa})$ were varied.Oil-water and water-rock zeta potentials were measured and used to calculateoil-rock disjoining pressures. $\mathrm{A}$ surface complexation model was developed to interpret contact angle measurements and compared with DLVO theory predictions.Contact angles were greatest in formation water, followed by the softened water, and low salinity water at the same pressure and temperature. Contact anglesincreased slightly with temperature, whereas pressure had little effect.DLVO and surface complexation modelling predicted similar wettability trends and allow reasonably accurate interpretation of core-flood results.

Keywords: Enhanced Oil Recovery, Low salinity water, High temperature, Disjoining pressure, Surface complexation model

\section{Introduction}

Lowering waterflood salinity, and $\mathrm{Ca}+\mathrm{Mg}$, is a potentially inexpensive means for recovering more oil from sandstones and, with some modifications, from carbonates(Austad, Rezaeidoust, \& Puntervold, 2010; Patrick V. Brady \& Krumhansl, 2012; Patrick Vane Brady, Krumhansl, \& Mariner, 2012; Patrick V. Brady et al., 2015; Cense, Berg, Bakker, \& Jansen, 2014; Jerauld, Webb, Lin, \& Seccombe, 2008; Mahani, Berg, Ilic, Bartels, \& Joekar-Niasar, 2014; Masalmeh et al., 2013; Myint \& Firoozabadi, 2015; Sheng, 2014; Sorop et al., 2014; Xie et al., 2015; Zhuoyan et al., 2015).Several mechanisms have been proposed to explain low salinity waterflooding (LSWF) including: fines mobilization (Tang \& Morrow, 1999), limited release of mixed-wet particles (Tang \& Morrow, 1999), increased pH and reduced IFT similar to alkaline flooding (McGuire, Chatham, Paskvan, Sommer, \& Carini, 2005), multicomponent ion exchange (MIE) (A.Lager, 2006; Lager, Webb, J. Black, Singleton, \& Sorbie, 2008; Lee et al., 2010; Seccombe, Lager, Webb, Jerauld, \& Fueg, 2008), double layer expansion (Ligthelm et al., 2009; Nasralla \& Nasr-El-Din, 2012; Xie, Liu, Wu, \& Liu, 2014), salt-in effect (RezaeiDoust, Puntervold, 
Strand, \& Austad, 2009), salting-out effect (Lashkarbolooki, Riazi, Hajibagheri, \& Ayatollahi, 2016) and osmotic pressure (Sandengen \& Arntzen, 2013).

LSWF at high temperatures, $>100{ }^{\circ} \mathrm{C}$, however, has rarely been investigated;most measurements have been done at lower temperatures. The lack of high temperature verification of LSWF is a significant research gap because very large quantities of crude oil are presentin high temperature reservoirs - for examplein the western part of China, the South China Sea and the Middle East. Moreover, traditionalchemicalEOR techniques such as polymer flooding and surfactant flooding are difficult to implement in high temperature reservoirs because of rapid chemical degradation (as well as economic and environmental factors), making LSWF a prime candidate for high temperature EOR. Early work suggestedno temperature limitations to LSWF (Rezaidoust et al. 2009). But insufficient data exists to predict LSWF performance at high temperatures.Our objectives here are therefore to verify LSWF at high temperatures, and determine what factors control wettability alteration in high temperature sandstone reservoirs.

Our focus is on the Tarim Field in western China. This sandstone reservoir has a high reservoir temperature of $140^{\circ} \mathrm{C}$, high formation water salinity of $142,431 \mathrm{ppm}$ total dissolved solids and an insitu oil viscosity of $2.2 \mathrm{cp}$. The porosity and permeability of the reservoir is in a range of $11-16 \%$ and 1-400 mD, respectively. The reservoir was discovered in July, 1990 and was brought to production in June 1994(Liu et al., 2016).In this study, we hypothesize that water chemistrycontrols wettability rather than reservoir temperature and pressure. To test this, we measuredcontact anglesbetween crude oil and reservoir rock in contact with different fluidsat 60,100 and $140{ }^{\circ} \mathrm{C}$, and $20,30,40$ and $50 \mathrm{MPa}$ pressure.DLVO theory and surface complexation models were applied to interpret the results.

\section{Materials and Methods}

\section{Experimental Fluids and Reservoir Rock}

Brines. To measurethe effect of water chemistries on reservoir wettability, three different brines were synthesized: formation brine, with a salinity of $142,431 \mathrm{ppm}$, formation brine softened by removing divalent, and low salinity water - formation brine diluted 100 times with distilled water (Table 1).

Table 1 Composition of experimental brines

\begin{tabular}{|c|c|c|c|c|c|c|c|c|}
\hline Brines & $\mathrm{K}^{+}$ & $\mathrm{Na}^{+}$ & $\mathrm{Ca}^{2+}$ & $\mathrm{Mg}^{2+}$ & $\mathrm{Cl}^{-}$ & $\mathrm{HCO}_{3}^{-}$ & $\mathrm{SO}_{4}^{2-}$ & $\mathrm{TDS}_{\mathrm{ppm}}$ \\
\hline Formation brine/FB & $1,152.0$ & $47,520.0$ & $5,840.0$ & 771.0 & $86,500.0$ & 586.7 & 61.5 & 142,431 \\
\hline Softened brine/SW & $1,152.0$ & $55,020.0$ & 0 & 0 & $85,500.0$ & 586.7 & 61.5 & 142,320 \\
\hline Low salinity water/LSW & 11.52 & 475.2 & 58.4 & 7.71 & 865 & 5.867 & 0.615 & $1,424.31$ \\
\hline
\end{tabular}

Crude Oil. The oil used in the contact angle measurements was obtained from a well head in a high temperature reservoir $\left(140^{\circ} \mathrm{C}\right)$ in the Tarim Field. The oil density under surface condition was measured to be $0.85 \mathrm{~g} / \mathrm{cm}^{3}$; oil viscosity was $5.23 \mathrm{mPa} . \mathrm{s}$, and the freezing point was $-20{ }^{\circ} \mathrm{C}$. The components with the polarized ends in crude oil included wax (3.58 wt \%) and asphaltene $(0.54$ wt \%). The reservoir oil has a base number of $1.3 \mathrm{mg} \mathrm{KOH} / \mathrm{g}$ and an acid number of $3.98 \mathrm{mg} \mathrm{KOH} / \mathrm{g}$.

Reservoir Rock. Table 2 shows the mineralogy and petrophyicial properties of the core taken from the field that was used in the contact angle measurements. Quartz was the most abundant mineralin the core, followed by clay, plagioclase, and dolomite. Trace amounts of orthoclase and 
calcite are observed in the reservoir. The clay fraction was made up of kaolinite (72\%), chlorite $(14 \%)$, and illite (14\%); there was nodetectable smectite.

Table 2 Minerology of reservoir core plug

\begin{tabular}{|c|c|c|c|c|}
\hline Sample & $\begin{array}{c}\text { Total Clay } \\
(\%)\end{array}$ & $\begin{array}{c}\text { Quartz } \\
(\%)\end{array}$ & $\begin{array}{c}\text { Plagioclase } \\
(\%)\end{array}$ & $\begin{array}{c}\text { Dolomite } \\
(\%)\end{array}$ \\
\hline CA-10 & 5.21 & 93.92 & 0.57 & 0.29 \\
\hline
\end{tabular}

\section{Contact Angle Test Procedure}

Oil-rock contact angles were measured using an IFT 700 (Vinci Technologies)(Figure 1) at 20, 30, 40, and $50 \mathrm{MPa}$ pressure, and $60,100,140{ }^{\circ} \mathrm{C}$. To limit measurement uncertainty due to minerology, we used the same substrate cut from the core plug (CA-10, with permeability of $0.65 \mathrm{mD}$, and porosity of $5.74 \%$ )to test the contact angle.

The experimental substratecut from the reservoir core plug was sanded with a fine grit sandpaper (800 US Mesh) to obtain a flat surface. Sandstone substrateswere then submerged in toluene and methanol to remove excess salt and organic contamination, rinsed with deionised water,put it in an oven to dry, then treated with air plasma for 10 minutes. The HP-HT IFT cell was thoroughly cleaned, as traces of contamination can significantly impact the measurements. The substrate was attached to the base of the holder using double compound high temperature epoxy glue, then the system was vacuumed for 30 minutes until pressure stabilised at 0.1 bar. The bulk phase brine and crude oil were degassed for 24 hours before being injected into the IFT cell using designated high precision hand pumps. The system were then heated to $60^{\circ} \mathrm{C}$ and pressurized to $20 \mathrm{MPa}$. As the temperature stabilised, the droplet formed via capillary needle and released on the surface of the substrate. The contact angle was measured after the contact angle stablished after 2 hours. The pressure, then, was adjusted to 30,40 and $50 \mathrm{MPa}$, and the corresponding contact angles were recorded. The same procedure was repeated for 100 and $140^{\circ} \mathrm{C}$.

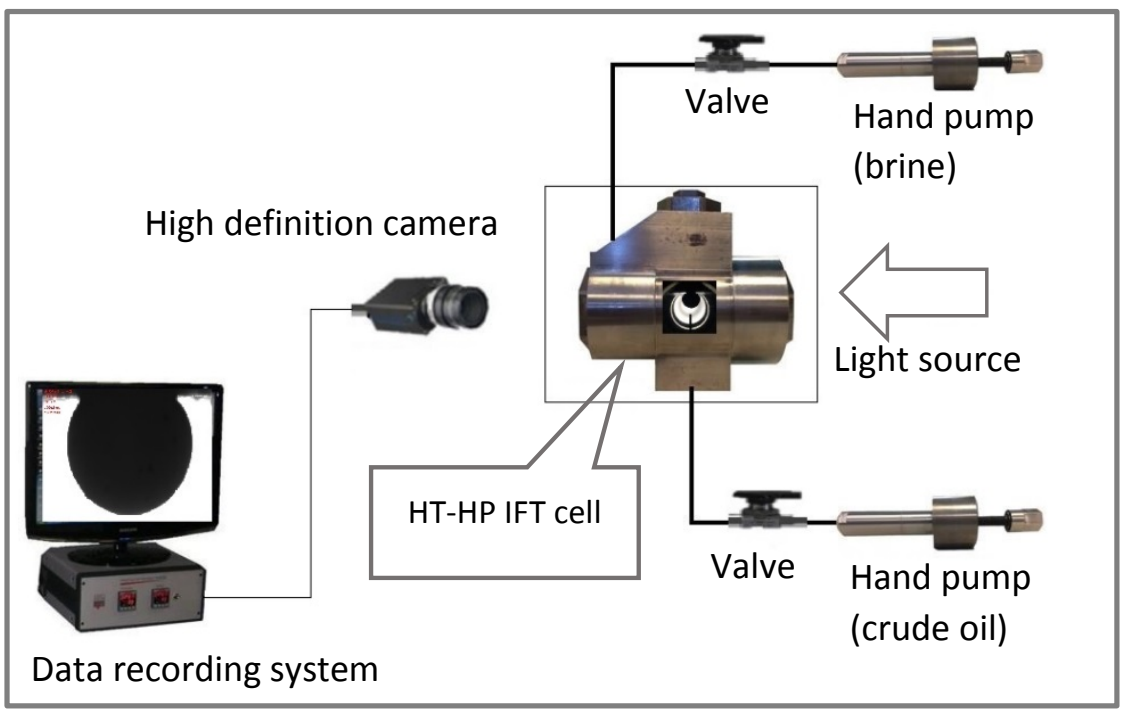

Figure 1 Schematic of high pressure and high temperature experimental set-up for contact angle measurements

\section{Zeta Potential Measurement}

To investigate the interplay between double layer expansion, surface complexation, and wettability alternationwe measured zeta potential (Zetasizer Nano ZS manufactured by Malvern)of theoil/brine 
and rock/brines interfacesfollowing the experimental protocol reported in the literature(Xie et al., 2014).

Measured zeta potentials are much more stable at $25^{\circ} \mathrm{C}$ than at high temperature due to the evaporation of brine at high temperature. Consequently, we used $25^{\circ} \mathrm{C}$ zeta potentials to examine the surface potential dependencies of oil and rock surface reactivity at higher temperatures given that zeta potentials tend to decrease uniformly with an increase in temperature(Schembre, Tang, \& Kovscek, 2006).

\section{Results and Discussion}

\section{Effect of Water Chemistries, Temperature, and Pressure on Contact Angle}

While water chemistry, temperature, and pressure all affected the contact angle, water chemistry had the largest impact (Figures2-4). For example, Figure 2 shows that the oil/rock contact angle in formation brine increased slightly with temperature, from $53^{\circ}$ to $63^{\circ}$, but was insensitive to pressure. Note that measurement error of $3 \%$ bar was showed in all of the contact angle tests due to the likely error generated by the surface roughness and unclear contact areas.

The softened brine contact angle was $\sim 10^{\circ}$ less than the formation brine contact angle at the same temperatures and pressures (Figure 3 ). Softened water shifted the wettability towards more waterwet, despitethe same salinity being the same. Similarly, lower contact angles, ranging from $29^{\circ}$ to $33^{\circ}$, were observed in the presence of low salinity water (Figure 4), suggesting that low salinity water makes the rock strongly water-wet.

Contact angles increased with temperature for all the brines, but the effect of temperature on the contact angle was not as pronounced as that of water chemistry. For example, the contact angle in the presence of formation brine increased from $53^{\circ}$ to $63^{\circ}$ as temperature was increased from 60 to $140{ }^{\circ} \mathrm{C}$ (Figure 2), suggesting that increasing temperature causes reservoir rock to become less water-wet. The same trend was observed in the presence of softened brine, where the contact angle varied from $39^{\circ}$ to $42^{\circ}$ (Figure 3 ) with increasing temperature. Similarly, the contact angle increased from $28^{\circ}$ to $33^{\circ}$ in the presence of the low salinity water as the temperature increased (Figure 4). These contact angle results are consistent with previous spontaneous imbibition and core-flooding tests on Tarim samples (Liu et al., 2016) whereinLSWFproducedan additional 14\% OOIP under secondary and tertiary modeby shifting wettability from slightly water-wet to strongly water-wet.

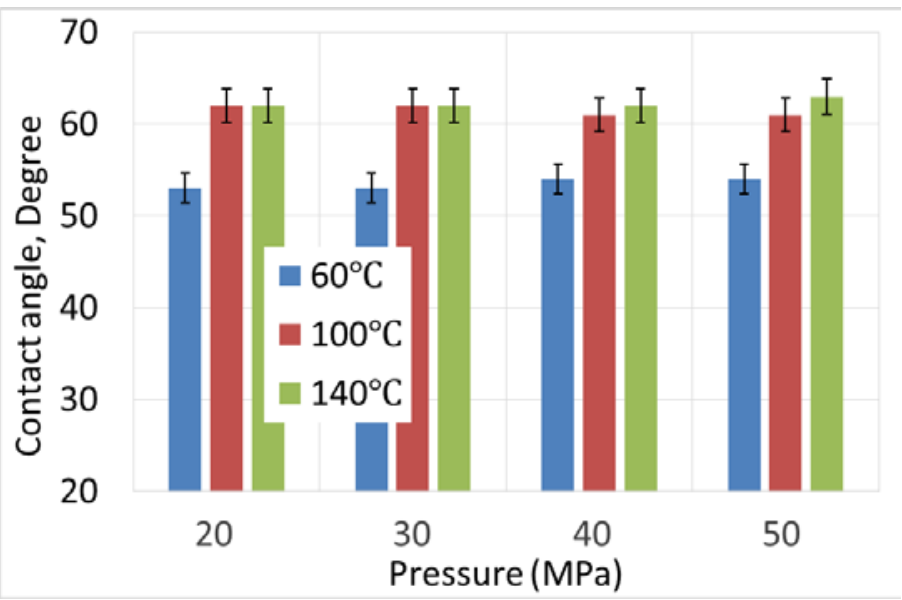

Figure 2.Formation brine contact anglesas a function of pressure and temperature 


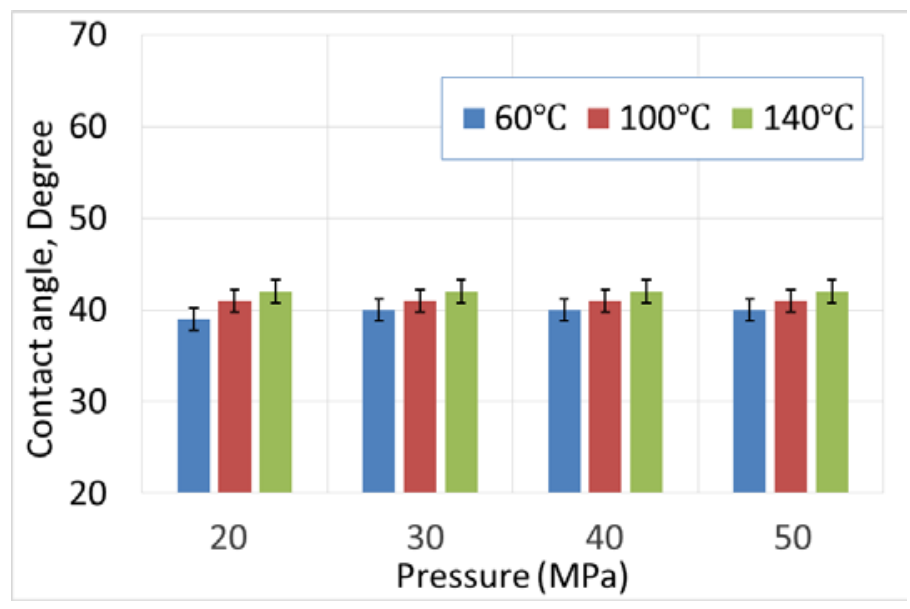

Figure 3. Softened brine contact anglesas a function of pressure and temperature

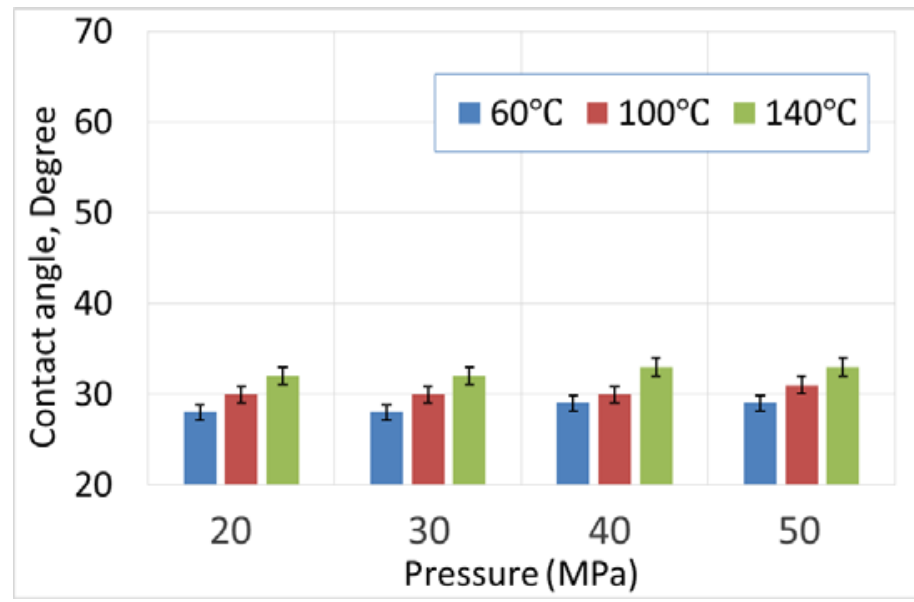

Figure 4.Low salinity water contact angles as a function of pressure and temperature

While the contact angle increased slightly with temperature, as seen previously(Roshan, Al-Yaseri, Sarmadivaleh, \& Iglauer, 2016), low salinity water decreased the contact angle significantly compared to that measured using the formation brine at reservoir conditions, confirming the effectiveness of LSWF in high temperature reservoirs. Theoretically, the contact angle is a function of disjoining pressure, which consists of double layer expansion force, Van-der-Waal attractive force and the structural force(Hirasaki, 1991). Brine water chemistry - salinity, $\mathrm{pH}$, and hardnessdominates the Debye-length and zeta potential. Decreasing the salinity causes the zeta potential of the oil-water and rock-water interfaces to become strongly negative (Nasralla \& Nasr-El-Din, 2014), thus resulting in a thicker double layer, which compensates the Van-der-Waal attractive force. Consequently, the reservoir becomes more water-wet (Xie, Saeedi, Pooryousefy, \& Liu, 2016). Despite the fact that the Van-der-Waal's force increases with the increase in temperature due to the increase in the Hamaker constant as a function of temperature, the increase of the Van-der-Waal's force may be much lower than the increase in double layer expansion force caused by low salinity water. This might explain whycontact angles increased slightly with temperature.

Note that the shift to water-wetness with low salinity water occured because of both the decrease in salinity and the lower concentration of divalent cations (Figure 4), as seen previously(Mahani et al., 
2015; Rashid, Mousapour, Ayatollahi, Vossoughi, \& Beigy, 2015; Xie et al., 2014). Divalent cations compress the double layer by decreasing zeta potential of both rock and oil, and thereby shift relative permeability curves towards higher residual oil saturation, in line with core-flooding experiments(Liu et al., 2016).

\section{Effect of Water Chemistry on Zeta Potential and Disjoining Pressure}

Zeta potentials of oil/fluid and rock/fluidinterfaces become more negative with decreasing salinity (Table 3 andFigure 5), indicating that the slip plane moves farther from each surface with decreasing salinity. This means that the double layer expansion force increases with the decline in salinity (Nasralla \& Nasr-El-Din, 2014; Xie et al., 2016). Removing divalent cations from the formation brine, but keeping the salinity level the same as the formation brine, resulted inonly a slight increase in negative zeta potential of the oil/rock and rock/fluid interfaces, pointing toCa+Mgadsorption compressing the respective electric double layers(Roshan et al., 2016).

Table3 Zeta potential of fluid-fluid and fluid-rock

\begin{tabular}{|l|c|c|c|c|}
\hline \multirow{2}{*}{ Samples } & \multicolumn{2}{|c|}{ Oil/water } & \multicolumn{2}{c|}{ Rock/water } \\
\cline { 2 - 5 } & Zeta potential $(\mathrm{mV})$ & $\mathrm{pH}$ & Zeta potential $(\mathrm{mV})$ & $\mathrm{pH}$ \\
\hline Formation brine & -1.89 & 6.2 & -3.56 & 6.2 \\
\hline Softened brine & -3.30 & 7.7 & -6.60 & 7.7 \\
\hline Low salinity water & -8.68 & 6.1 & -19.27 & 6.6 \\
\hline
\end{tabular}

Given that water chemistries affect the calculated Debye Length and zeta potential, which in return impact the double layer expansion, we examined the effect of water chemistries on disjoining pressure to interpret the contact angle change with solution chemistry. Hirasaki investigated the thermodynamics of the thin films to determine the interdependence of spreading, contact angle and capillary pressure using the DLVO theory and Laplace-Young Equation (Hirasaki, 1991). The intermolecular forces comprise of the van der Waals, electrical and structural forces (Busireddy \& Rao, 2004; Hirasaki, 1991). However, we did not consider the structural forces due to the fact that the structural forces are short-range interactions over a distance of less than $5 \mathrm{~nm}$ compared with the London-van der Waals and electrical double layer forces which are considered are long-range interactions (Israelachvili, 2011).

$$
\Pi_{\text {Total }}=\Pi_{\text {electrical }}-H / 6 \pi L^{3}
$$

Where $\Pi_{\text {Total }}$ is the disjoining pressure of the specific intermolecular interactions which reflects the interactive forces between the interfaces of water/oil and water/rock. $\Pi_{\text {electrical }}$ is the electrostatic force as a results of the development of the charges between interacting surfaces. A brief introduction of the forces and calculation procedures were presented in a literature(Xie et al., 2016).The Hamaker constant for oil/silica in water is approximately $1 \times 10^{-20} \mathrm{~J}$ (Hirasaki, 1991). Melrose (Melrose, 1982) used Hamaker constants ranging from 0.3 to $0.9 \times 10^{-20} \mathrm{~J}$. In this study, $0.81 \times 10^{-20} \mathrm{~J}$ was used as the Hamaker constant, and the London wavelength is assumed to be 100 nm (Hirasaki, 1991).

Disjoining pressure calculation showed that both formation brine and softened brine gave negative disjoining pressure (completely overlapped), and monotonically decrease with increase of the separation distance (i.e., are purely attractive), although the interface of oil/brine and brine/rock were negatively charged (Figure 6). This is consistent with the results(Xie et al., 2016), showing that $50,000 \mathrm{ppm} \mathrm{NaCl}$ brine solution generated negative disjoining pressure in the oil/brine/clay system. 
This implies that both softened brine and formation brine compress the double layer significantly due to the high salinity level $(142,431 \mathrm{ppm})$.

However, low salinity water caused a progressively more repulsive condition at increasingly close separation disjoining pressure. The salinity decrease causes the disjoining pressure profile to shift outward and dilate due to reduced electrostatic screening, consistent with the behaviour reported in the literature for kaolinite sample(Patrick V. Brady et al., 2015). Consequently, the low salinity water shifts the wettability of reservoir rock towards more water-wet, in line with the contact angle results. Yet, the question still remains why the oil/rock contact angle in softened brine was smaller than the contact angle in the formation brine when the disjoining pressure calculation predicted there should be little difference.

Note that zeta potential and double layer expansion are less sensitive to the ratio of divalent to monovalent cations when the salinity level is above 50,000 ppm(Xie et al., 2016). Otherwise, salinity level would dominate the disjoining pressure rather than ion charge, in line with our calculation of disjoining pressure. This probably explainswhy no difference incalculated disjoining pressure was observed. In sum, while DLVO accounts for the increase in oil and rock negative zeta all oil/rock/fluid interaction. A surface complexation model of the oil and rock interfaces was potential with low salinity water, and theresultant double layer expansion, DLVO does not completely explain developed to further examine the low salinity effect (see below).

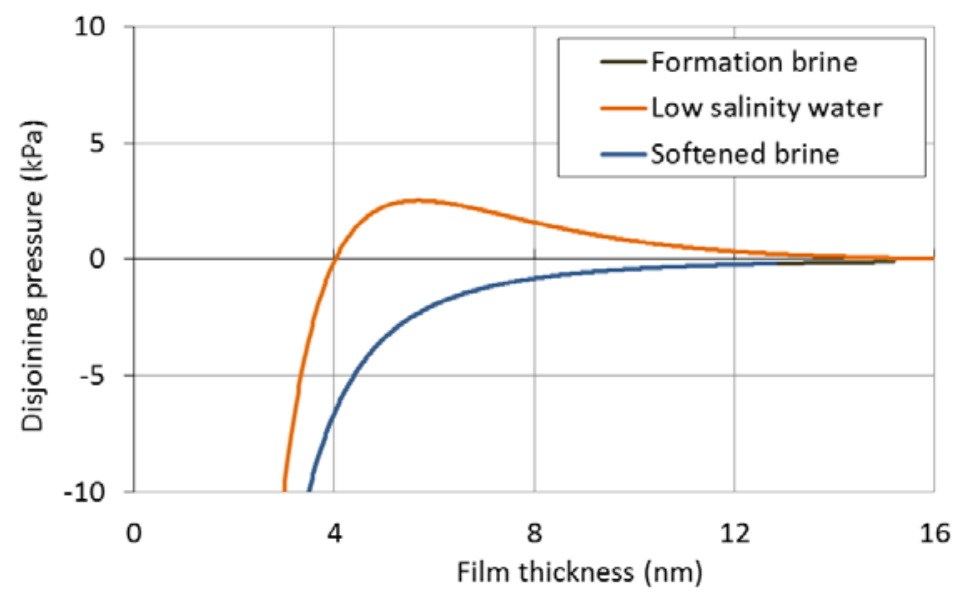

Figure 5.Calculated total disjoining pressure under constant reduced potential vs. interfacial separation of reservoir rock and oil for formation brine, softened brine, and low salinity water.The formation brine and softened brine overlap completely.

\section{Surface Complexation Analysis}

Acomplementaryapproach to using zeta potentials and double layer thickness calculations to interpret wettability alterationis to use coordination chemistry. By this method, surface complexation models were developed for the oil and rock interfaces to identify the individual charged species that give rise to oil and rock zeta potentials, and then used to calculate the degree of electrostatic attraction between the oil and rock (Brady and Krumhansl, 2012). DLVO theory and surface complexation modellingare equivalent in that they both recognize an electric double layer and the existence of charged surface species whose concentrations depend upon the chemical makeup of the water and the oil and mineral. Consequently, the two approaches typically predict similar trends. A key attraction of the surface complexation approach is that it quantifies surface 
species and wettability alteration in units of moles/L, which can be readily used to link fluid chemistry changes to changes in wettability. DLVO-based analyses instead quantify wettability in more less wieldyterms of pressure, slip-plane thicknesses, and/or voltages.

A surface complexation approach for the oil and sandstonepresumes that oil binds to the reservoir through two electrostatic bridges involving: positively charged oil nitrogen base groups $\left(-\mathrm{NH}^{+}\right)$and negatively charged kaolinite edge sites ( $\left.>\mathrm{X}-\mathrm{O}^{-}\right)$; and between oil $-\mathrm{COOCa}^{+}$groups and anionic kaolinite edge sites, where oil coordinates to the rock surface. Large numbers of electrostatic bridges means oil wetting and high contact angles. Fewer electrostatic bridges means water wetting and low contact angles. The number of electrostatic bridges is calculated as a function of $\mathrm{pH}$ and salinity using surface complexation models of the oil-water and kaolinite-water interfaces.

Figure 6 shows oil charged surface species at 60 and $140{ }^{\circ} \mathrm{C}$ calculated using a diffuse layer model of the oil-water interface, the surface equilibrium constants and reaction enthalpies of Brady and Krumhansl (2012), the measured acid and base numbers for Tarim oil, and the geochemical speciation code PHREEQC (Parkhurst et al., 1999). Kaolinite surface area was set to $10 \mathrm{~m}^{2} / \mathrm{g}$; oil surface area was set to $0.1 \mathrm{~m}^{2} / \mathrm{g}$. The Tarim oil surface is dominated by carboxyl groups, - $\mathrm{COO}^{-}$(not shown) and Ca-terminated carboxyl groups, $-\mathrm{COOCa}^{+}$. Only at lower $\mathrm{pH}$ are cationic nitrogen bases, $\mathrm{NH}^{+}$, calculated to form appreciably.Positively charged surface species are plotted because they are the most likely to electrostatically interact with negatively charged kaolinite edges.

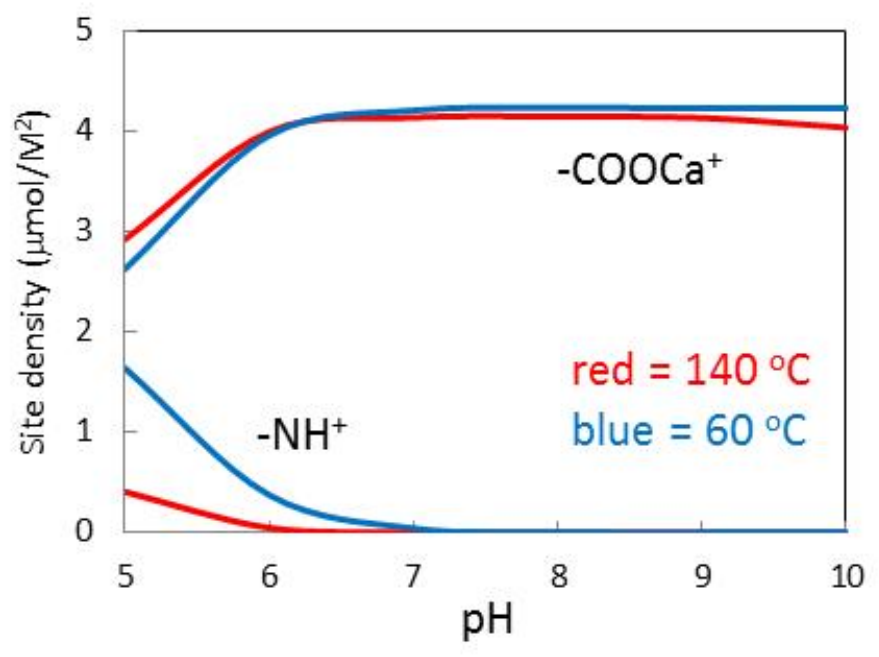

Figure 6. Calculated $60^{\circ} \mathrm{C}$ (dashed lines) and $140{ }^{\circ} \mathrm{C}$ (solid lines) Tarim oil charged surface species in Tarim formation water.

Figure 7 shows $140{ }^{\circ} \mathrm{C}-\mathrm{COOCa}^{+}$site densities calculated for the high salinity formation water, and the low salinity solution. The decreased $\mathrm{Ca}^{2+}$ concentration of the lower salinity solution decreases the number of $-\mathrm{COOCa}^{+}$groups at the oil surface. 


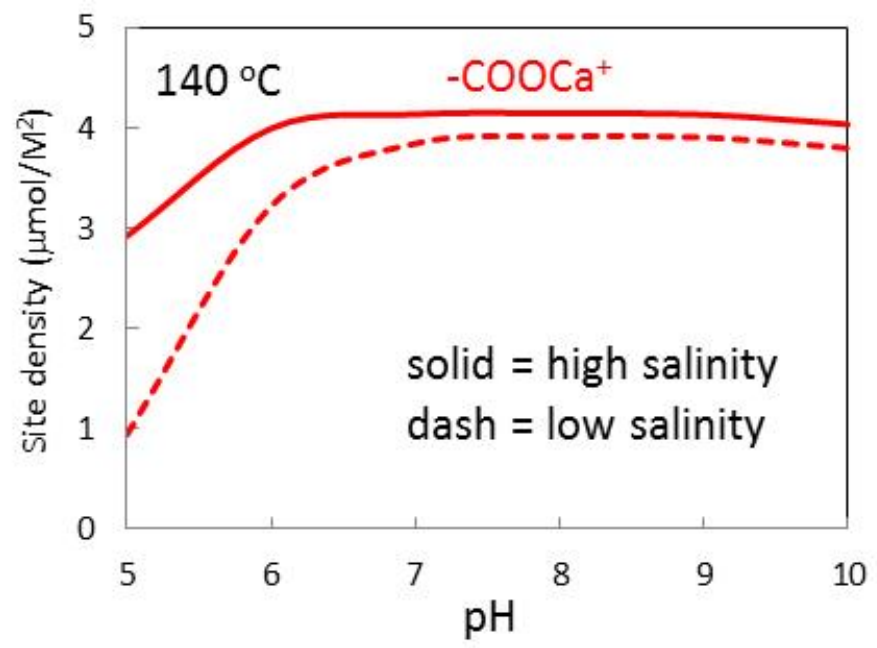

Figure 7. Calculated 140 oC (solid lines) Tarim oil $-\mathrm{COOCa}^{+}$concentration in Tarim high salinity formation water and low salinity water.

Calculated kaolinite anionic edge charge, $>\mathrm{X}-\mathrm{O}$, is shown as a function of temperature, $\mathrm{pH}$, and salinity in Figure 8 . Note that except at very high $\mathrm{pH}$, edge charge became increasingly anionic with increasing salinity.

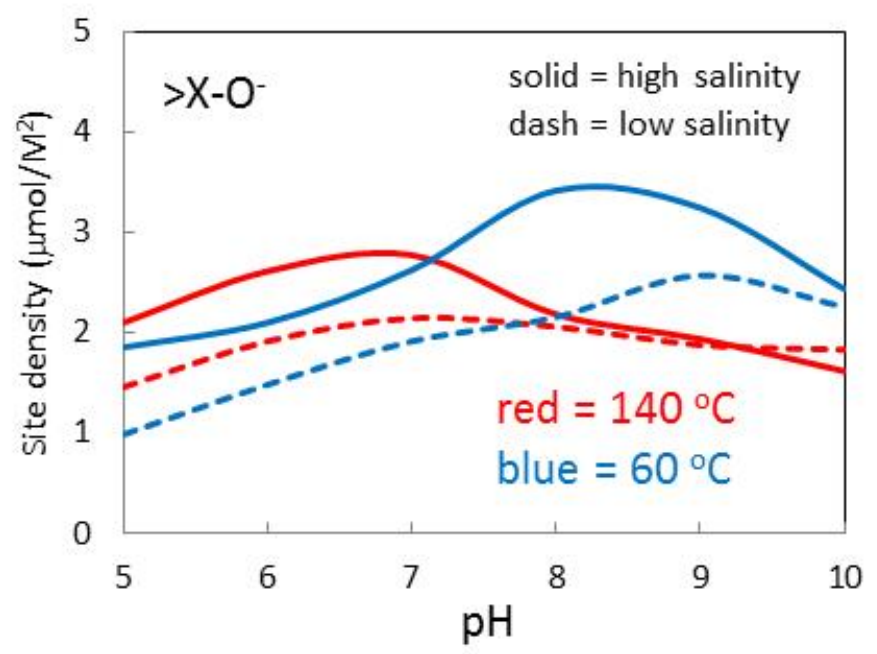

Figure 8. Calculated kaolinite anionic edge density as a function of temperature and $\mathrm{pH}$ in high salinity formation water and low salinity water.

Figure 9 sums the number of electrostatic bridges (the bond product sum) between oil and kaolinite edges as a function of temperature, $\mathrm{pH}$, and salinity to estimate adhesion. 


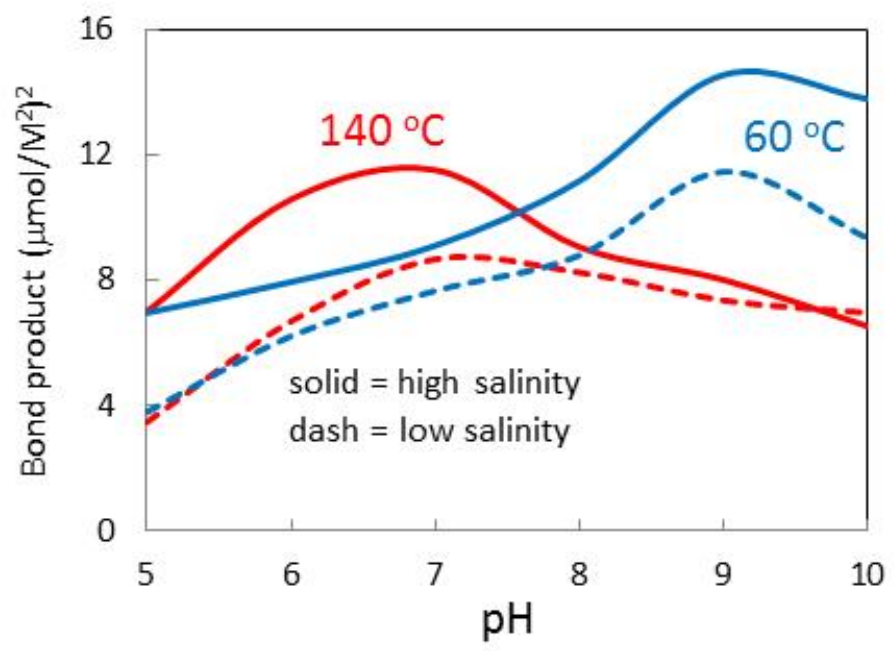

Figure 9. Calculated oil-kaolinite bond product sum as a function of temperature and pH in high salinity formation water and low salinity water.

The bond product calculations in Figure 9 link oil and rock surface electrostatics to wettability and recovery. Specifically, a LSWF works for the Tarim field(Liu et al., 2016) because it decreases the number of oil $-\mathrm{COOCa}^{+}$- kaolinite $>\mathrm{XO}^{-}$bridges by decreasing the concentration of the individual charged oil and kaolinite sites. The surface complexation approach accurately reproduces the formation water and low salinity contact angle results. Moreover, the slight dependence of contact angles on temperature and pressure can be explained by the fact that the oil and kaolinite surface complexation constants are themselves relatively insensitive to temperature and pressure. The results in Figure 9 do not explain the contact angles measured in softened water, which the analysis above predicts should be smaller (more water-wet) than the low salinity water (See Figure 10). In fact, the softened water contact angles are greater than the low salinity contact angles. Two potential explanations for the discrepancy are that:

1. In situ pHs during the contact angle measurements were on the low side. Note that at $\mathrm{pH}<$ 5.2 the calculated bond products are in the correct order seen in the contact angle measurements.

2. $-\mathrm{COOCa}^{+} \mid>\mathrm{XO}^{-}$interactions are weaker than $-\mathrm{NH}^{+} \mid>\mathrm{XO}^{-}$interactions.

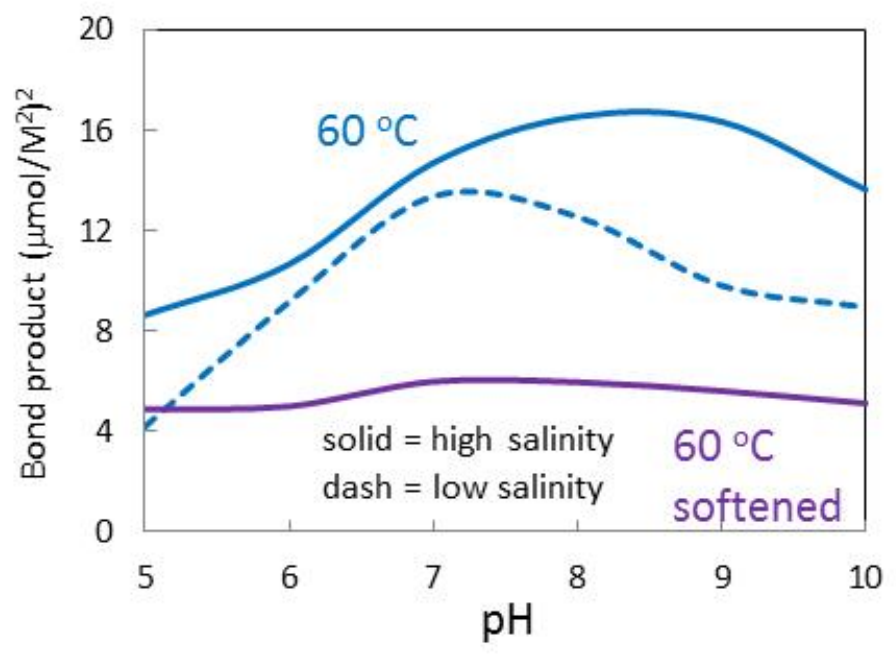


Figure 10. Calculated oil-kaolinite $60^{\circ} \mathrm{C}$ bond product sum as a function ofpH in high salinity formation water, low salinity water, and softened water. Equilibrium with calcite was assumed in this calculation.

The calculated bond products were the sum of $-\mathrm{COOCa}^{+} \mid>\mathrm{XO}^{-}$and $-\mathrm{NH}^{+} \mid>\mathrm{XO}^{-}$interactions, and they were weighted equally. One could make the bond product calculation reproduce the relative order of all the contact angle measurements by weighing the $-\mathrm{NH}^{+} \mid>\mathrm{XO}^{-}$interactions more than the $\mathrm{COOCa}^{+} \mid>\mathrm{XO}^{-}$interactions. This might be the case simply because a $-\mathrm{COOCa}^{+} \mid>\mathrm{XO}^{-}$bridge is likely to be longer, hence weaker, than an $-\mathrm{NH}^{+} \mid>\mathrm{XO}^{-}$bridge. But a more quantitative analysis remains to be made.

The surface complexation analysis does provide an explanation for why some LSWF's don't work. For example, an illite+kaolinite-bearing sandstone with $110^{\circ} \mathrm{C}$ high salinity formation waters of $\sim 200,000$ ppm showed no LS EOR effects, with either seawater (SW) or 50 times diluted seawater (Aghaeifar et al., 2015) , except when a particularly sharp increase in $\mathrm{pH}$ was observed. The null result is probably caused by the low acid number, $0.25 \mathrm{mg} \mathrm{KOH} / \mathrm{g}$, of the crude oil. A low acid number means fewer-COOCa ${ }^{+}$groups at the oil/brine interface, hence far fewer $\mathrm{COOCa}^{+}$bridges to the negatively charged clay basal planes in the pre-waterflood state to begin with. Subsequent injection of Ca-poor water should have had little impact on wettability. The LS EOR effect that was observed was likely caused by $\mathrm{pH}$-dependent release of oil $-\mathrm{NH}^{+}$groups from negatively charged clay sites, a process that requires a pH increase to be observed(Patrick V. Brady \& Krumhansl, 2012).

\section{Implications of the Results}

DLVO says $\mathrm{Ca}^{2+}$ compresses the double layer which allows the oil and clay to approach more closely and coordination (Nasralla \& Nasr-El-Din, 2014; Xie et al., 2016). Surface complexation says that $\mathrm{Ca}^{2+}$ electrostatically links oil and clay bringing them closer as a result. In both models, increasing $\mathrm{Ca}^{2+}$ increases oil-clay adhesion.

DLVO says increasing salinity compresses the double layer, allowing the oil and clay to approach more closely and coordinate. Surface complexation says that increasing salinity increases the site density of oppositely charged surface species which makes oil and clay link more strongly. In both models, increasing salinity increases oil-clay adhesion.

Surface complexation says that $\mathrm{pH}$ changes the number of charged surface species at oil and clay surfaces which increases oil-clay adhesion in those cases where the surface species on the oil and clay are oppositely charged. DLVO says that $\mathrm{pH}$ changes the zeta potential, thus alters the double layer expansion and disjoining pressure. For example, zeta potential for both fluid-fluid and fluidrock becomes more negative as the $\mathrm{pH}$ increases, thereby increasing the double layer expansion and lift off the oil film from rock surface (Patrick V. Brady et al., 2015).

Generally, DLVO and surface complexation predict similar wettability trends because the physics behind them is the same. We argue that combining the two theories would provide an excellent complement to traditional core-flooding test, thus constraining the intrinsic uncertainty of low salinity water flooding in reservoir scale.

\section{Conclusions}

To decipher the factors controlling wettability alteration bylow salinity water flooding in high temperature reservoirs, we measured the effect of water chemistry, temperature, and pressure on contact angle between crude oil and sandstone. The crude oil had a base number of $1.3 \mathrm{mg} \mathrm{KOH} / \mathrm{g}$ and acid number of $3.98 \mathrm{mg} \mathrm{KOH} / \mathrm{g}$. The reservoir is at $140^{\circ} \mathrm{C}$; the formation salinity is $142,431 \mathrm{ppm}$. 
Oil-rock contact angle was measured in formation brine, 100X diluted formation brine at 60, 100 and $140{ }^{\circ} \mathrm{C}$ and $20,30,40$ and $50 \mathrm{MPa}$.

While water chemistry, temperature and pressure, all affected the contact angle to some degrees, water chemistry played a dominant role, thus expanding the application envelop of low salinity water flooding to high temperature $\left(>100^{\circ} \mathrm{C}\right)$ reservoirs. Disjoining pressure calculations showed that low salinity water exhibited a progressively more repulsive barrier at increasingly close separation disjoining pressure, suggesting that LSWFmakes the rock more water wet, consistent with the contact angle experiments. Surface complexation modelling showed that increasing salinity and $\mathrm{Ca}^{2+}$, increases the site density of oppositely charged surface species which makes oil and clay link more strongly. Together, DLVO and surface complexation modelling predict similar wettability trends, showing that water chemistries controls interaction of crude oil/brine/rock rather than temperature and pressure, particularly for crude oils with high acid number, in line with contact angle tests. We also argue that combining the two theories would provide an excellent complement to traditional core-flooding test, thus constraining the intrinsic uncertainty of low salinity water flooding in reservoir scale.

\section{Acknowledgement}

This work is supported by Open Fund (PLN201603) of State Key Laboratory of Oil and Gas Reservoir Geology and Exploitation (Southwest Petroleum University), and PetroChina Tarim Oilfield Company. Authors give thanks to the PhD student Noor Zaouri for zeta potential test in the Curtin Water Quality Research Centre. Authors also give thanks to the PhD student Ahmad Sari and Intertek GEOTECH for the measurements of experimental oil acid number and base number. Support from Sandia National Laboratories is also highly appreciated. Sandia is a multiprogramlaboratory operated by Sandia Corporation, a Lockheed MartinCompany, for the United States Department of Energy'sNational Nuclear Security Administration under contract DEAC04-94AL85000.

\section{References}

A.Lager, K. J. W., C.J.J.Black, M.Singleton, K.S.Sorbie. (2006). Low salinity oil recovery-an experimental investigation. SCA2006-36.

Aghaeifar, Z., Strand, S., Austad, T., Puntervold, T., Aksulu, H., Navratil, K., ... Håmsø, D. (2015). Influence of Formation Water Salinity/Composition on the Low-Salinity Enhanced Oil Recovery Effect in High-Temperature Sandstone Reservoirs. Energy \& Fuels. doi:10.1021/acs.energyfuels.5b01621

Austad, T., Rezaeidoust, A., \& Puntervold, T. (2010). Chemical Mechanism of Low Salinity Water Flooding in Sandstone Reservoirs. Paper presented at the SPE Improved Oil Recovery Symposium, Tulsa, Oklahoma, USA.

Brady, P. V., \& Krumhansl, J. L. (2012). A surface complexation model of oil-brine-sandstone interfaces at $100^{\circ} \mathrm{C}$ : Low salinity waterflooding. Journal of Petroleum Science and Engineering, 81(0), 171-176. doi:http://dx.doi.org/10.1016/j.petrol.2011.12.020

Brady, P. V., Krumhansl, J. L., \& Mariner, P. E. (2012). Surface Complexation Modeling for Improved Oil Recovery. Paper presented at the SPE Improved Oil Recovery Symposium, Tulsa, Oklahoma, USA.

Brady, P. V., Morrow, N. R., Fogden, A., Deniz, V., Loahardjo, N., \& Winoto. (2015). Electrostatics and the Low Salinity Effect in Sandstone Reservoirs. Energy \& Fuels, 29(2), 666-677. doi:10.1021/ef502474a

Busireddy, C., \& Rao, D. N. (2004). Application of DLVO Theory to Characterize Spreading in Crude Oil-Brine-Rock Systems. Paper presented at the SPE/DOE Symposium on Improved Oil Recovery, Tulsa, Oklahoma. 
Cense, A., Berg, S., Bakker, K., \& Jansen, E. (2014). Direct Visualization of Designer Water Flooding in Model Experiments. https://www.onepetro.org/conference-paper/SPE-144936-MS

Hirasaki, G. J. (1991). Wettability:fundamentals and surface forces. SPE Formation Evaluation, 6(2), 217-226.

Israelachvili, J. N. (2011). Chapter 13 - Van der Waals Forces between Particles and Surfaces. In J. N. Israelachvili (Ed.), Intermolecular and Surface Forces (Third Edition) (pp. 253-289). San Diego: Academic Press.

Jerauld, G., Webb, K., Lin, C. Y., \& Seccombe, J. (2008). Modeling low-salinity waterflooding. SPE Reservoir Evaluation \& Engineering, 11(6), 1000-1012.

Lager, A., Webb, K., J. Black, C., Singleton, M., \& Sorbie, K. (2008). Low Salinity Oil Recovery-An Experimental Investigation1. Petrophysics, 49(1).

Lashkarbolooki, M., Riazi, M., Hajibagheri, F., \& Ayatollahi, S. (2016). Low salinity injection into asphaltenic-carbonate oil reservoir, mechanistical study. Journal of Molecular Liquids, 216, 377-386. doi:http://dx.doi.org/10.1016/j.molliq.2016.01.051

Lee, S. Y., Webb, K. J., Collins, I., Lager, A., Clarke, S., O'Sullivan, M., ... Wang, X. (2010). Low Salinity Oil Recovery: Increasing Understanding of the Underlying Mechanisms. Paper presented at the SPE Improved Oil Recovery Symposium, Tulsa, Oklahoma, USA.

Ligthelm, D., Gronsveld, J., Hofman, J., Brussee, N., Marcelis, F., \& van der Linde, H. (2009). Novel Waterflooding Strategy By Manipulation Of Injection Brine Composition.

Liu, Y., Jiang, T., Zhou, D., Zhao, J., Xie, Q., \& Saeedi, A. (2016). Evaluation of the Potential of Low Salinity Water Flooding in the High Temperature and High Salinity Dong-He-Tang Reservoir in the Tarim Oilfeild, China: Experimental and Reservoir Simulation Results.

Mahani, H., Berg, S., Ilic, D., Bartels, W.-B., \& Joekar-Niasar, V. (2014). Kinetics of Low-SalinityFlooding Effect. doi:10.2118/165255-PA

Mahani, H., Keya, A. L., Berg, S., Bartels, W.-B., Nasralla, R., \& Rossen, W. R. (2015). Insights into the Mechanism of Wettability Alteration by Low-Salinity Flooding (LSF) in Carbonates. Energy \& Fuels, 29(3), 1352-1367. doi:10.1021/ef5023847

Masalmeh, S. K., Sorop, T. G., Suijkerbuijk, B. M., Vermolen, E. C., Douma, S., van der Linde, H., \& Pieterse, S. (2013). LOW SALINITY FLOODING: EXPERIMENTAL EVALUATION AND NUMERICAL INTERPRETATION. SCA2013-022.

McGuire, P., Chatham, J., Paskvan, F., Sommer, D., \& Carini, F. (2005). Low Salinity Oil Recovery: An Exciting New EOR Opportunity for Alaska's North Slope.

Melrose, J. (1982). Interpretation of mixed wettability states in reservoir rocks. Paper presented at the SPE Annual Technical Conference and Exhibition.

Myint, P. C., \& Firoozabadi, A. (2015). Thin liquid films in improved oil recovery from low-salinity brine. Current Opinion in Colloid \& Interface Science, 20(2), 105-114. doi:http://dx.doi.org/10.1016/i.cocis.2015.03.002

Nasralla, R. A., \& Nasr-El-Din, H. A. (2012). Double-Layer Expansion: Is It A Primary Mechanism of Improved Oil Recovery by Low-Salinity Waterflooding? Paper presented at the SPE Improved Oil Recovery Symposium, Tulsa, Oklahoma, USA.

Nasralla, R. A., \& Nasr-El-Din, H. A. (2014). Impact of cation type and concentration in injected brine on oil recovery in sandstone reservoirs. Journal of Petroleum Science and Engineering, 122, 384-395.

Rashid, S., Mousapour, M. S., Ayatollahi, S., Vossoughi, M., \& Beigy, A. H. (2015). Wettability alteration in carbonates during "Smart Waterflood": Underlying mechanisms and the effect of individual ions. Colloids and Surfaces A: Physicochemical and Engineering Aspects, 487, 142-153. doi:http://dx.doi.org/10.1016/j.colsurfa.2015.09.067

RezaeiDoust, A., Puntervold, T., Strand, S., \& Austad, T. (2009). Smart water as wettability modifier in carbonate and sandstone: A discussion of similarities/differences in the chemical mechanisms. Energy \& Fuels, 23(9), 4479-4485. 
Roshan, H., Al-Yaseri, A., Sarmadivaleh, M., \& Iglauer, S. (2016). On Wettability of Shale Rocks. Journal of colloid and interface science.

Sandengen, K., \& Arntzen, O. (2013). Osmosis During Low Salinity Water Flooding. Paper presented at the IOR 2013-From Fundamental Science to Deployment.

Schembre, J. M., Tang, G. Q., \& Kovscek, A. R. (2006). Wettability alteration and oil recovery by water imbibition at elevated temperatures. Journal of Petroleum Science and Engineering, 52(1-4), 131-148. doi:http://dx.doi.org/10.1016/j.petrol.2006.03.017

Seccombe, J., Lager, A., Webb, K., Jerauld, G., \& Fueg, E. (2008). Improving Wateflood Recovery: LoSalTM EOR Field Evaluation.

Sheng, J. J. (2014). Critical review of low-salinity waterflooding. Journal of Petroleum Science and Engineering, 120(0), 216-224. doi:http://dx.doi.org/10.1016/i.petrol.2014.05.026

Sorop, T., Parker, A. R., Chmuzh, I. V., Masalmeh, S. K., Suijkerbuijk, B., Skripkin, A., . . Karpan, V. (2014). Low Salinity Waterflooding at West Salym: Laboratory Experiments and Field Forecasts. Paper presented at the SPE EOR Conference at Oil and Gas West Asia.

Tang, G.-Q., \& Morrow, N. R. (1999). Influence of brine composition and fines migration on crude oil/brine/rock interactions and oil recovery. Journal of Petroleum Science and Engineering, 24(2-4), 99-111. doi:http://dx.doi.org/10.1016/S0920-4105(99)00034-0

Xie, Q., Liu, Y., Wu, J., \& Liu, Q. (2014). Ions tuning water flooding experiments and interpretation by thermodynamics of wettability. Journal of Petroleum Science and Engineering, 124(0), 350358. doi:http://dx.doi.org/10.1016/j.petrol.2014.07.015

Xie, Q., Ma, D., Wu, J., Liu, Q., Jia, N., \& Luo, M. (2015). Potential Evaluation of Ion Tuning Waterflooding for a Tight Oil Reservoir in Jiyuan OilField: Experiments and Reservoir Simulation Results. https://www.onepetro.org:443/download/conference-paper/SPE174584-MS?id=conference-paper\%2FSPE-174584-MS

Xie, Q., Saeedi, A., Pooryousefy, E., \& Liu, Y. (2016). Extended DLVO-based estimates of surface force in low salinity water flooding. Journal of Molecular Liquids, 221, 658-665. doi:http://dx.doi.org/10.1016/j.molliq.2016.06.004

Zhuoyan, Z., Quan, X., Hanbing, X., Jian, F., Feng, W., Juedu, A., . . Dehai, H. (2015). Evaluation of the Potential of High-Temperature, Low-Salinity Polymer Flood for the Gao-30 Reservoir in the Huabei Oilfield, China: Experimental and Reservoir Simulation Results. https://www.onepetro.org/conference-paper/OTC-25817-MS 